\title{
Perfil e PRÁtica docente das PROfessoras QUe ENSINAM CiÊnCIAS NOS ANOS INICIAIS DO ENSINO Fundamental
}

TEACHING PROFILE AND PRACTICE OF TEACHERS TEACHING SCIENCES IN THE INITIAL SERIES

DOI: http://dx.doi.org/10.23926/RPD.2526-2149.2019.v4.n2.p578-593.id433

\author{
Sheila Alves Almeida \\ Doutorado em Ensino de \\ Ciências e Matemática \\ (USP) \\ Professora Adjunta do \\ Departamento de \\ Biodiversidade, Evolução e \\ Meio Ambiente (UFOP) \\ Orienta pesquisas no \\ Programa de Pós Graduação \\ do Mestrado em Educação \\ no ICHS. \\ sheilaalvez@uol.com.br
}

Resumo: Este trabalho tem como objetivo apresentar o perfil e as atividades valorizadas pelas professoras que ensinam ciências nos anos iniciais do ensino fundamental na cidade de Mariana-MG. A coleta de dados foi realizada por meio da aplicação de questionários distribuídos a 55 professoras de escolas públicas. A análise dos resultados mostrou que, apesar da grande maioria das professoras possuir curso superior e, portanto, ter frequentado disciplinas metodológicas sobre o ensino de ciências, o curso não influenciou suas práticas. Conclui-se que, embora as professoras não neguem a importância das aulas de Ciências, esse conhecimento não possui o mesmo status das aulas de português e matemática. Para as professoras pesquisadas, atividades experimentais como as realizadas nas aulas de Ciências não se constituem parte do cotidiano de suas práticas pedagógicas, embora não neguem a importância dessa disciplina.

Palavras-chave: Formação de professoras; ensino de ciências; anos iniciais do Ensino Fundamental.

\begin{abstract}
This paper aims to present the profile and activities valued by teachers who teach science in the early years of elementary school in the city of Mariana-MG. Data collection was performed by applying questionnaires distributed to 55 teachers from public schools. The analysis of the results showed that, although the vast majority of the teachers had a college degree and, therefore, attended methodological disciplines about science teaching, the course did not influence their practices. It is concluded that although the teachers do not deny the importance of science classes, this knowledge does not have the same status as Portuguese and math classes. For the teachers researched, experimental activities such as those performed in science classes are not part of the daily routine of their pedagogical practices, although they do not deny the importance of this discipline. Keywords: Teacher training; science education; early years of elementary school.
\end{abstract}




\section{INTRODUÇÃO}

Nos últimos 20 anos, tem ocorrido uma avalanche de mudanças a respeito das formas pelas quais as crianças aprendem o que reflete nas diretrizes curriculares, no material didático e também nas práticas de sala de aula. Nesse movimento de mudança, as teorias construtivistas, ao lado da formação dos professores bem como a metodologia parecem compor o tripé que sustenta a discussão sobre o ensino de ciências nos anos iniciais do Ensino Fundamental na atualidade. No bojo dessas discussões, as atividades práticas nas aulas de Ciências sempre surgem como alternativa em face das metodologias tradicionais. Em geral, estudos têm apontado a deficiência na formação das professoras e a prioridade da alfabetização e da matemática como os principais fatores do insucesso do ensino de Ciências nos primeiros anos.

No Brasil, apesar da crescente produção, de diferentes áreas do conhecimento, estudos que investigam o ensino de Ciências para as crianças são mais reduzidos. Um estudo importante nessa área foi realizado por Fernandes (2009). Em sua investigação, descreve e analisa as tendências das pesquisas direcionadas ao ensino de Ciências nas fases iniciais de escolarização, durante o período de 1972 a 2005, buscando traçar o panorama dessa produção, ao longo das décadas. Ele constatou um aumento significativo de trabalhos sobre o ensino dessa disciplina nos anos iniciais; dos 135 trabalhos encontrados, 112 foram defendidos na última década, isto é, $83 \%$ do total. No entanto, a autora alerta que esse resultado é reflexo do aumento da pesquisa acadêmica e que as investigações em ciências nos anos iniciais do Ensino Fundamental ainda representam uma pequena parcela.

Embora os livros didáticos de Ciências para os anos iniciais tenham apresentado avanços significativos para orientar a prática pedagógica dessa disciplina, esses avanços aparecem na sala de aula de forma mais formal que real. Assim sendo, o ensino dessa disciplina segue com muitos questionamentos em torno das práticas pedagógicas desenvolvidas.

Considerando que a seleção e a orientação das atividades dependem, em última instância, do professor, pretendemos, com este trabalho, investigar quais atividades e procedimentos são utilizados e valorizados pelos professores dos anos iniciais nas aulas de Ciências. Para tanto, formulamos as seguintes perguntas: quem são as professoras da referida disciplina nos iniciais do Ensino Fundamental? Há quanto tempo trabalham com essa área de conhecimento? Qual é a sua formação? Qual é a frequência das aulas de Ciências? Quais as práticas pedagógicas adotadas? Para responder a essas questões, construímos uma proposta teórico-metodológica com vistas a articular dados da sala de aula, obtidos por meio de um questionário. Assim, o objetivo deste estudo recai no levantamento do perfil das professoras e 
na análise das práticas das professoras que ensinam Ciências nos anos iniciais na Rede Pública de Ensino da cidade de Mariana-MG buscando compreender os sentidos que elas atribuem a essa disciplina.

\section{REFERENCIAL TEÓRICO}

Sathres e colaboradores (2006) ressaltam que a formação dos professores que ensinam Ciências nos anos iniciais do ensino fundamental é preocupante. Consequentemente, é necessário pensar numa mudança de postura na elaboração do planejamento, uma vez que é nítido o interesse das crianças por essa área do conhecimento. Aliás, outros estudiosos têm manifestado preocupação com a formação de professores.

Augusto e Amaral (2015), por exemplo, indicam, em suas investigações, que a formação do pedagogo é generalista, com foco nas metodologias em detrimento de embasamento teórico dos conceitos científicos. Essa formação reflete na sua atuação no ensino de Ciências Naturais. Já para Weissmann (1998), a dificuldade no trabalho dos professores dos anos iniciais é quanto à prioridade do que será ensinado. Em linhas gerais, os professores desse nível de ensino priorizam as disciplinas Matemática e Português em detrimento de Ciências Naturais.

Em adição, as pesquisas realizadas por Fumagalli (1998) indicam que o ensino de Ciências é conduzido por meio de aulas expositivas, com explicações de forma superficial. É centrado na memorização e em definições prontas, expostas de forma compartimentada, disciplinares em relação com ao contexto social, histórico e cultural.

Em seus estudos sobre a formação das professoras que ensinam Ciências, Delizoicov e colaboradores (2005) indicam que os conteúdos mais citados pelos professores são: corpo humano - ligado aos mais variados aspectos relacionados a ele; meio ambiente; plantas e animais; água e solo; saúde e higiene. Ressaltam Delizoicov et, al (2005) que a literatura tem demonstrado pouco as áreas específicas do conhecimento nos currículos dos curso de formação de professores destinado aos anos iniciais do ensino fundamental. Os conteúdos das áreas específicas são, geralmente, abordados nas respectivas disciplinas de metodologias de ensino, e, na maioria das vezes, durante apenas um semestre.

Por sua vez, Coquidé (2008) chama a atenção para o fato de que o déficit de formação apontado pela maioria das pesquisas que tratam das professoras que ensinam ciências não parece suficiente para explicar as suas concepções. Para essa autora, as professoras não são alheias às defasagens de suas práticas. Acrescenta que elas não só discutem as exigências da 
promoção de atividades científicas autênticas como também têm consciência da necessidade de abertura para as mudanças.

Lima e Maués (2006) argumentam que o foco do ensino de Ciências nos anos iniciais não está no conhecimento do conteúdo. Para esses autores, as professoras utilizam estratégias para ensinar conteúdos pouco familiares que são eficazes para promover o desenvolvimento e aprendizagem das crianças. Afirmam esses autores:

\begin{abstract}
Esses professores são capazes de mobilizar saberes das outras áreas de conhecimento (matemática, alfabetização, conhecimentos pedagógicos gerais) para desenvolver atividades significativas, estimulando a criatividade das crianças, favorecendo sua interação com o mundo, ampliando seus conhecimentos prévios, levantando e confrontando os conhecimentos dos alunos. Assim, mesmo não tendo um domínio adequado do conteúdo de ciências, conseguem estabelecer uma mediação de qualidade entre as crianças e os objetos de conhecimento (Lima e Maués, 2005, p.166).
\end{abstract}

Assim, considerando a necessidade de conhecer o contexto e as práticas cotidianas das professoras, esperamos que este estudo, propicie a discussão de sua formação no tocante ao ensino de Ciências.

\title{
3 Metodologia
}

Para atender aos objetivos desta investigação, realizamos uma pesquisa quantitativa em 7 escolas públicas da cidade de Mariana, sendo quatro pertencentes à Rede Municipal de Ensino e três à Rede Estadual. Em relação à pesquisa quantitativa, Gatti (2004) chama atenção para a sua importância uma vez que há problemas educacionais que necessitam ser qualificados por meio de dados quantitativos. Destaca, ainda, que o uso das bases de dados existentes sobre educação é muito pequeno pela dificuldade dos educadores em lidar com dados demográficos e com medidas de um modo geral. Para essa autora, um dos riscos da pesquisa quantitativa está associado ao modo pelo qual são analisadas as relações entre as macroinstâncias e microinstâncias, ora dicotomizando-as e pensando a autonomia de uma dessas instâncias diante da outra, ora estabelecendo relações causais imediatas entre elas. Trata-se de um risco inevitável considerando-se que nem sempre podemos escapar de tais questões metodológicas. Por outro lado, Alves Mazzoti (2001) ressalta a importância de investigações quantitativas em situações em que o pesquisador lida com um fenômeno sobre o qual já existe conhecimento acumulado por outras pesquisas em contexto semelhante. Salienta a autora que a identificação de padrões não é incompatível com estudos de fenômenos microssociais. Por conseguinte, é preciso ressaltar as investigações de Barros e Losada (2001), realizadas na Espanha, com o uso de questionário, e com o mesmo objetivo do nosso trabalho e, nas quais inspiramos não invalidam 
este trabalho. Os resultados da pesquisa desses autores indicaram que todos os professores desenvolvem, em suas salas de aula atividades escritas (questões e exercícios); 96\% declararam que também realizam atividades práticas (observações ou experiências); 74,9\% reconheceram a utilização de meios audiovisuais e $84,7 \%$ realizam atividades em pequenos grupos. As professoras declararam insegurança quanto a sua formação.

Diferente da pesquisa de Barros e Losada (2001), que envolveu mais de 500 professores em diferentes escolas da região da Coruña, nossa investigação ficou circunscrita a uma região da cidade de Mariana/MG. Com efeito, a escolha das escolas para a aplicação dos questionários decorreu das condições da investigação: disposição das professoras para responder ao questionário e possibilidade de acesso, sem muitas dificuldades, a um número significativo de professoras. No entanto, isso só foi possível sendo os questionários aplicados apenas em algumas escolas da cidade de Mariana cujo acesso era mais fácil. De outro modo, o questionário não permitiu compreender, em toda a sua complexidade, a prática das professoras. Isso não significa, entretanto, que ele não tenha possibilitado a apreensão de certas nuanças do perfil e das práticas das professoras que dão aulas de Ciências nos primeiros anos do Ensino Fundamental.

Quanto à produção do questionário, elaboramos 20 perguntas sobre: a formação das professoras; o tempo destinado às aulas de Ciências; os conteúdos desenvolvidos nas aulas; a realização de atividades práticas; as formas de organização e interação nas aulas; o uso do livro didático; o objetivo das atividades, entre outras. Acompanhava o questionário um termo de consentimento que tem como objetivo permitir a compreensão da pesquisa e seus procedimentos, bem como assegurar aos participantes que as informações obtidas serão utilizadas respeitando o anonimato dos depoentes, servindo exclusivamente para fins de produção de conhecimento. O questionário foi composto, em grande parte, por questões de múltipla-escolha de modo a viabilizar o tempo e disposição das professoras para essa tarefa. As questões sobre formação e atividades práticas foram as únicas perguntas abertas.

Explicitadas essas questões, o nosso primeiro grande desafio foi a distribuição desse material nas escolas. Primeiramente nos dirigimos à Secretaria Municipal de Educação de Mariana para solicitar a autorização para aplicação dos questionários aos professores. Conforme a orientação recebida pela Secretaria, realizamos a aplicação e o recolhimento dos questionários no período de 29 de fevereiro a 15 de março de 2017, período em que essa tarefa foi realizada também nas escolas da Rede Estadual. 
Vale lembrar que os questionários foram entregues aos docentes para serem respondidos sem sua identificação. Em cada uma das 7 escolas, selecionamos as professoras que seriam alvo da investigação - professoras dos anos iniciais que ministravam Ciências. Chegamos à listagem final com um total de 85 nomes. Essa lista foi um instrumento importante para a identificação das professoras que poderiam participar desse processo e garantir maior controle na distribuição e coleta dos questionários.

Destacamos, ainda, que fomos bem recebidas em todas as escolas e a princípio todos se mostraram dispostos a colaborar com a investigação. No entanto, muitas professoras não devolveram o material na data marcada, justificando-se que "esqueceram a data, não tiveram tempo e que esqueceralm o questionário em casa”. Esse fato fez com que retornássemos cinco vezes às escolas para que o objetivo da pesquisa fosse alcançado. Assim, dos 85 questionários distribuídos, conseguimos um total de 55 questionários devolvidos. Esse resultado mostra que, embora tenha existido alguma resistência por parte de algumas professoras para responder às perguntas, o resultado foi significativo e acima das expectativas: um retorno de aproximadamente $65 \%$ dos docentes devolveram os questionários.

Com relação às perguntas desse instrumento, as primeiras foram relativas às questões mais gerais do perfil dos professores que atuam no ensino de Ciências nos anos iniciais. A partir da questão número 11, as perguntas foram direcionadas à frequência das aulas e finalidades das atividades propostas. As perguntas abertas, foram pertencentes ao âmbito conceitual, procedimental e atitudinal. De posse desses dados, as respostas obtidas foram transcritas, interpretadas e analisadas.

\section{Resultados}

De modo geral, as aulas nos anos iniciais do Ensino Fundamental são ministradas por mulheres. A propósito, de Macedo (2004), Albuquerque (2002), UNESCO (2004) apontam a feminização como uma característica própria do magistério do ensino fundamental. Na visão de Carvalho (1996: 13 apud Unesco, 2004), o fato de a maioria dos professores do Ensino Fundamental corresponder a mulheres produz marcas dessa presença feminina na caracterização do grupo de profissionais da escola, nas formas de ensino, nas relações estabelecidas entre os diferentes atores que dão materialidade à escola. Segundo a autora, as marcas estão relacionadas não só ao predomínio da emoção e da afetividade na visão do mundo e do trabalho docente, como também a uma postura defensiva e conservadora diante ao novo. No entanto, em sua dissertação de mestrado, Almeida (2005) considera que essa postura 
defensiva se deve ao cuidado das professoras e à responsabilidade perante o ofício de ensinar. Portanto, 55 mulheres - professoras participaram desta pesquisa, motivo pelo qual fazemos sempre o uso do feminino ao referir a esse público.

Quanto à idade, as professoras estão distribuídas, em sua maioria, no intervalo de $30 \mathrm{a}$ 42 anos, perfazendo um total de 50 professoras. Resultados também semelhantes encontramos nos estudos da UNESCO (2004), ou seja, a média de idade dos docentes é de 37,8 anos, o que, considerado o panorama internacional, coloca os professores brasileiros como relativamente mais jovens (UNESCO, 2004).

Com referência à formação das professoras, a maioria possui curso superior, num total de 96,4\%. Esse dado relaciona-se, entre outros fatores, à Lei de Diretrizes e Bases, de 1996, que colocou em pauta a exigência da formação de nível superior para as professoras dos anos iniciais. Tal exigência desencadeou a discussão pelo do de carreira, que estabelece uma diferença salarial para professores de nível superior e, paralelamente, da política do Ministério de Educação, que determina a formação superior para o ingresso na carreira do magistério. A propósito, nos últimos 7 anos $45 \%$ dos docentes concluíram o ensino superior.

Desse modo, o curso Normal Superior é predominante na formação acadêmica dessas professoras, correspondendo a $44 \%$ do total de professoras com a formação em nível superior. Em segundo lugar, na categoria "outros cursos de graduação" se inserem $24 \%$ na amostra. Vale lembrar que o curso de Pedagogia da Universidade Federal de Ouro Preto (UFOP) é bem recente na região. Esse fato talvez explique os baixos índices de professoras com o curso de Pedagogia. É importante ressaltar que 3 professoras possuem 2 graduações. Apenas $4 \%$ indicaram a formação em ensino médio no magistério. A respeito do tipo de estabelecimento que conferiu o título para a prática docente, predomina de titulação das professoras em instituições federais, correspondendo a 55\% da amostra, seguida da formação em instituições particulares, que corresponde a 33\%. Esses dados seguem a tendência da pesquisa sobre o perfil das professoras brasileiros realizada pela UNESCO em 2004. A maior parte das professoras concluiu o curso na modalidade presencial, mas os dados revelam que um número significativo (47\%), conclui nas modalidades a distância ou semipresencial.

Também, nos últimos dois anos, 29\% das professoras realizaram cursos de capacitação em alfabetização e letramento. Em ciências, apenas $9 \%$ das professoras realizaram cursos de atualização. Nesse caso, as professoras, com exceção de uma, indicaram cursos na área de educação ambiental. E uma professora indicou a realização de um curso em astronomia. Do total de professoras, 33\% realizaram cursos em outras áreas de conhecimento e $29 \%$ não 
realizou nenhum curso nos últimos dois anos de docência. Concluímos, assim, que mais de 70\% das professoras realizaram algum tipo de curso ou capacitação. No entanto, no tocante ao ensino de Ciências, os números não chegam a 10\% e, além disso, com relevância a uma temática que, provavelmente, não abrange, com profundidade, ideias da didática desse ensino.

Em relação ao tempo na docência, do conjunto das professoras investigadas, $85 \%$ estão na docência há mais de 10 anos. Elas trabalham, predominantemente, em apenas uma escola (75\%). Isso, porém, não significa que trabalhem em um único turno, pois podem trabalhar em dois turnos numa mesma escola. Em relação à frequência das aulas de Ciências, a maioria das professoras afirma que trabalham com essa disciplina toda a semana, com diferentes duração de tempo $(98,2 \%)$. Quanto à distribuição da carga horária, as escolas determinam para as aulas de Ciências 2 aulas semanais, e a maioria das professoras segue o número de aulas estabelecido pelas instituições (45,5\%). Apenas uma professora leciona aulas de Ciências às crianças 4 vezes por semana. Provavelmente, nesse caso, essa professora trabalhe com o ensino de Ciências em várias salas. Apenas uma professora indica que raramente ministra essas aulas. No entanto, somente a análise da situação real de ensino poderá evidenciar como essas formas de organização são construídas na sala de aula e como elas vinculam-se aos processos de ensino e aprendizagem. Essa frequência das aulas de Ciências pode ser observada na tabela abaixo:

Tabela 1 - Tabela 1: frequência das aulas de Ciências

\begin{tabular}{lcc}
\hline Frequência das aulas de Ciências na semana & Total & $\mathbf{\%}$ \\
\hline Diariamente & 0 & 0 \\
4 vezes por semana & 1 & 1,8 \\
3 vezes por semana & 9 & 16,4 \\
2 vezes por semana & 25 & 45,5 \\
1 vez por semana & 19 & 34,5 \\
Raramente & 1 & 1,8 \\
\hline Total global & $\mathbf{5 5}$ & $\mathbf{1 0 0}$ \\
\hline
\end{tabular}

Fonte: Da pesquisa.

Esses dados corroboram os estudos de Nigro e Azevedo (2011). Os autores denunciam a desvantagem entre o ensino de Ciências e o ensino da leitura e escrita. Destacam o escasso tempo dedicado às aulas de Ciências, apesar dessa disciplina também fornecer o suporte básico para o ensino da leitura escrita, meta dos primeiros anos de escolarização. Nessa direção, a pesquisa do Game (1998) sobre o perfil das professoras dos anos iniciais, realizada em todo o Estado de Minas Gerais, também mostra o menor tempo dedicado ao ensino de Ciências em relação à Matemática e ao Português. De acordo com Game fica evidente que quanto maior a legitimidade social da disciplina que compõe o currículo escolar, maior é o tempo que as professoras dedicam ao seu ensino (GAME, 1998). No entanto, essa discussão sobre a 
distribuição da carga horária é complexa. Nos primeiros anos de escolarização, o processo de alfabetização, no sentido estrito do termo, demanda tempo, portanto, é compreensível que a carga horária para estudos da língua materna seja superior. Talvez, nos anos iniciais do Ensino Fundamental, o tempo destinado às aulas de Ciências não deveria ser o ponto central das discussões, mas sim as práticas pedagógicas que compõem o letramento escolar. Desse modo, um artigo de divulgação científica para crianças pode e deve ser trabalhado pensando nos objetivos da alfabetização, que é o foco da educação das crianças dos ciclos iniciais. Também, ensinar as crianças a escrever um texto a partir da observação de um inseto ou apresentar oralmente e por escrito um experimento constituem atividades importantes que contemplam a aprendizagem das diferentes linguagens. Assim, o tempo dedicado a essa matéria na escola necessita ser pensado levando em consideração os propósitos educacionais desse ensino e as características do pensamento das crianças.

Como apontado anteriormente, a grande maioria das professoras ministra aulas de Ciências nos anos iniciais há mais de 10 anos (85\%). Esse dado sobre o tempo de experiência com o ensino dessa disciplina é revelador haja vista que as professoras, mesmo sendo consideradas generalistas, se especializam em algumas áreas ao longo de sua experiência na escola. Portanto, esse dado contradiz o que foi constatado por Gatti et al (1994), ao afirmar que as professoras do ensino fundamental, no Brasil, tendem a variar as áreas de conhecimento, não se dedicando a nenhum trabalho específico.

Em relação à frequência das atividades práticas realizadas nas aulas de Ciências, a tabela a seguir mostra que elas acontecem ocasionalmente (69\%). Considerando a importância dessas atividades para o ensino de Ciências, esse dado merece ser investigado. Tais atividades demandam tempo de preparação o que pode dificultar a sua realização. Também, a concepção de ensino de Ciências e a falta de material na escola podem afetar essas práticas. O grupo que afirma que desenvolve atividades práticas pelo menos uma vez por mês, somados os intervalos semanais, quinzenais e mensais equivale a $31 \%$. Esse percentual permite supor que menos da metade das professoras recorre às famosas experiências com certa regularidade em seu ensino. No entanto, é importante observarmos que todas as professoras, em algum momento, recorreram às atividades práticas em suas aulas de Ciências. Vejamos os dados da tabela abaixo: 
Tabela 2 - Uso de atividades práticas nas aulas de Ciências

\begin{tabular}{lcc}
\hline Utilização de atividades práticas nas aulas & Total & \% \\
\hline Semanalmente & 7 & 12,7 \\
Quinzenalmente & 4 & 7,3 \\
Mensalmente & 6 & 11,0 \\
Ocasionalmente & 38 & 69,0 \\
Nunca & 0 & 0,0 \\
\hline Total global & $\mathbf{5 5}$ & $\mathbf{1 0 0}$ \\
\hline
\end{tabular}

Fonte: Da pesquisa.

Em resposta à pergunta sobre a fonte que consultam para a utilização das atividades práticas, a maioria das professoras indicou o livro didático. Também a experiência docente aparece como estratégia para as escolhas e sites da internet que abordam temáticas de ciências.

Acerca da questão 'com que finalidade as atividades práticas são realizadas nas aulas de Ciências, as professoras especificaram, por escrito, qual(is) era(m) o(s) objetivo(s) das experiências. Após a leitura de todas as respostas, definimos as categorias de análise, conforme apresentadas na Tabela 3 a seguir. Elas representam o conjunto de ideias apresentadas pelas professoras. Um grupo de 3 professoras (5,5\% da nossa amostra) não respondeu a esta questão. Dentre os objetivos citados, a concepção que prevaleceu em relação às experiências nas aulas de Ciências foi de que a ciência nos proporciona conhecer a realidade, indício de uma concepção empirista. À guisa de ilustração, vejamos a tabela abaixo:

Tabela 3 - As experiências nas aulas de Ciências

\begin{tabular}{rlcc}
\hline O papel das "experiências" nas aulas de Ciências & Total & \% \\
\hline a. & Despertar a curiosidade & 15 & 27,3 \\
b. Descoberta do conhecimento & 11 & 20,0 \\
c. Fixar e sistematizar o conhecimento & 24 & 43,6 \\
d. Construir conhecimentos & 2 & 3,6 \\
e. Não respondeu & 3 & 5,5 \\
\hline Total global & & $\mathbf{5 5}$ & $\mathbf{1 0 0}$ \\
\hline
\end{tabular}

Fonte: Da pesquisa.

Embora a maioria das professoras tenha apresentado uma concepção empirista das atividades práticas, observamos, nesse mesmo grupo, uma variação dos objetivos conferidos às experiências. As professoras que apontaram que as práticas serviam para despertar a curiosidade, em geral, destacaram que as experiências serviam para seduzir, estimular, envolver, encantar. Portanto, para essas professoras, as práticas são importantes mais pelo aspecto lúdico do que pelo cognitivo. E, para $20 \%$ das professoras pesquisadas, as atividades práticas como propiciam a descoberta do conhecimento. Em adição, mencionaram que as experiências auxiliam as crianças a colocarem para fora o pensamento, aguçar a curiosidade e identificar o conteúdo trabalhado. O olhar das docentes parece se voltar para o fazer e não o 
compreender das crianças nas atividades. Por fim, $43,6 \%$ veem as atividades práticas como validação das teorias. Assim, para esse grupo, as aulas práticas são importantes para que as crianças vivenciem a teoria na prática, ou melhor, "vejam com seus próprios olhos", confirmem o conteúdo, evidenciem o conhecimento, comprovem a teoria. Apenas duas professoras citaram a construção do conhecimento, o debate e a construção de argumentos como tópico importante no trabalho com atividades práticas.

Com referência às principais dificuldades para o desenvolvimento das atividades práticas nas aulas de Ciências, docentes apontaram: a falta de laboratório, de espaço adequado e material específico para as aulas. Vale lembrar que consideramos a primeira indicação das professoras na resposta para a construção dessa categoria. Nesse caso, temos:

Tabela 4 - Dificuldades para a realização das atividades práticas

\begin{tabular}{rlcc}
\hline Dificuldades encontradas para a realização das atividades & Total & $\mathbf{\%}$ \\
\hline a. & Falta de laboratório & 17 & 31,0 \\
b. & Falta de materiais & 14 & 25,4 \\
c. & Falta de materiais específicos & 7 & 12,7 \\
d. & Falta de espaço & 4 & 7,3 \\
e. & Organização de material & 4 & 7,3 \\
f. Nenhuma & 7 & 12,7 \\
g. Atividades pouco valorizadas na escola & 1 & 1,8 \\
h. Compreensão a linguagem dos livros & 1 & 1,8 \\
\hline Total global & & $\mathbf{5 5}$ & $\mathbf{1 0 0}$ \\
\hline
\end{tabular}

Fonte: Da pesquisa.

Apesar de um número expressivo de professoras (31\%) destacar, como principal dificuldade, a falta de laboratório para a realização de trabalhos práticos, Borges e Moraes (1998) argumentam que a existência de laboratório nas escolas não é garantia de uso desse espaço para a realização de aulas práticas. Para esses autores, o trabalho de laboratório não significa apenas trabalho no laboratório. Segundo esses autores, bons trabalhos de laboratório podem ser conduzidos em salas de aula comuns. A aula prática deve se caracterizar pela participação intelectual ativa do estudante. Por outro lado, essa reivindicação das professoras é curiosa, haja vista que os cursos de formação superior em Pedagogia ou Magistério Superior não enfatizam as aulas em laboratório. Talvez essa reivindicação seja uma representação do que as professoras entendem por aulas de práticas em ciências.

Quanto ao dado ausência de material optamos por separar as professoras que indicaram a ausência de material e das que se referiram a materiais específicos por não saber o que é, exatamente, um e outro. Será que as professoras ao citarem materiais específicos se referiram a kits para o ensino de Ciências? Ou será que tudo se enquadra em uma única categoria? É 
interessante observar que o percentual de professoras que reivindicam materiais e materiais específicos para as aulas práticas é grande. Somadas as duas categorias o resultado é $45,4 \%$ da amostra.

Voltando aos resultados, do total da amostra, apenas 12,7\% não veem nenhuma dificuldade para a realização das atividades práticas. Esse número coincide com o percentual que realiza atividades práticas pelo menos uma vez por mês. A organização do material também é um fator apontado como dificultador no trabalho, pois a realização de uma prática depende não só da existência do material, mas também de tempo e lugar adequados para a sua organização. Esses fatores afetam a lógica de organização e distribuição de tempo na escola.

Por outro lado, duas professoras fizeram referência a aspectos ligados à realização das atividades: uma, à compreensão da linguagem do livro didático, e outra, à valorização dessas atividades pela escola. No tocante à linguagem do livro, parece-nos necessário analisar o livro e as atividades a que essa professora se refere. E no tocante à valorização das atividades pela escola, é sabido que muitas interpretam atividades em que as crianças se movimentam, falam e fazem barulho como indisciplina e, consequentemente, falta de habilidade da professora na lida com a turma. Desse modo, esse tipo de atividade não é valorizado pelas escolas que não compreendem o que as crianças podem aprender com as atividades práticas. Assim, essa concepção é construída pelas professoras em seu espaço de trabalho.

Os dados relativos às habilidades desenvolvidas nas aulas de Ciências mostram que o trabalho com o texto e oralidade são estratégias mais presentes nas aulas. Aliás, a leitura e discussão do texto é a prática mais recorrente entre os docentes. A grande maioria $(96,4)$ afirma o uso dessa estratégia. Também o debate é apontado como uma habilidade bastante presente nas aulas. Mas não nos pareceu claro o que as professoras chamam de debate nas aulas de Ciências. Esse dado parece estar relacionado ao discurso pedagógico que considera as conversas em torno de um assunto como debate. E, quanto ao uso do livro didático, a maioria das professoras, semanalmente, utilizam seus exercícios em suas aulas (87,3). A nosso ver, esse dado parece incoerente com aquele que indica a fixação dos nomes e conceitos científicos. É importante considerar que menos de $20 \%$ das professoras trabalham com o uso de instrumentos nas aulas. 
Tabela 5 - Habilidades e competências desenvolvidas nas aulas

\begin{tabular}{llccccccccc}
\hline Habilidades e competências desenvolvidas nas aulas & \multicolumn{2}{c}{$\begin{array}{c}\text { Uma vez } \\
\text { p/semana }\end{array}$} & \multicolumn{2}{c}{$\begin{array}{c}\text { Uma vez } \\
\text { p/mês }\end{array}$} & \multicolumn{2}{c}{$\begin{array}{c}\text { Uma vez p/ } \\
\text { bimestre }\end{array}$} & \multicolumn{2}{c}{ Nunca } \\
\hline & no & $\%$ & no & $\%$ & no & $\%$ & no & $\%$ \\
a. & Copiar textos do livro didático ou do quadro & 36 & 65,5 & 2 & 3,6 & 1 & 1,8 & 16 & 29,1 \\
b. & Conversar sobre textos de jornais e revistas & 45 & 82,0 & 9 & 16,4 & 1 & 1,8 & 0 & 0,0 \\
c. & Fazer exercícios do livro didático & 48 & 87,3 & 1 & 1,8 & 0 & 0,0 & 6 & 11,0 \\
d. & Ler e discutir um texto & 53 & 96,4 & 1 & 1,8 & 0 & 0,0 & 1 & 1,8 \\
e. & Fixar os nomes de conceitos científicos & 22 & 40,0 & 15 & 27,3 & 4 & 7,2 & 14 & 25,5 \\
f. & Registrar informações a partir de trab. prát. & 18 & 32,0 & 13 & 24,0 & 6 & 11,0 & 18 & 33,0 \\
\hline
\end{tabular}

Fonte: Da pesquisa

Como mostra a tabela acima, as professoras aqui pesquisadas, atribuem enorme valor às atividades de leitura e escrita nas aulas de Ciências, como mostra as investigações de Garcia e Losada (2001). Esses autores sugerem que isso ocorre porque os professores se sentem inseguros para realizar atividades diferentes em sala de aula. Conforme a análise dos dados acima, as atividades de leitura e discussão dos textos predominam $(96,4)$. Por outro lado, é surpreendente que apenas $32 \%$ trabalhem com o registro de informações nas aulas práticas. Um número significativo de professoras (82\%), afirmou a presença de textos de jornais e revistas com frequência nas aulas de Ciências. Eis um dado que precisa ser investigado. Perguntamos, então: quais são os instrumentos utilizados pelas professoras, além do livro didático e textos fotocopiados? Os exercícios do livro didático e atividades de cópia ocupam lugar de destaque nas aulas?

A tabela a seguir mostra outras habilidades que as professoras desenvolvem nas aulas de Ciências.

Tabela 6 - Habilidades e competências desenvolvidas nas aulas

\begin{tabular}{|llcccccccc}
\hline $\begin{array}{l}\text { Habilidades e competências desenvolvidas nas } \\
\text { aulas }\end{array}$ & \multicolumn{2}{c}{$\begin{array}{c}\text { Uma vez } \\
\text { p/semana }\end{array}$} & $\begin{array}{c}\text { Uma vez } \\
\text { p/mês }\end{array}$ & $\begin{array}{c}\text { Uma vez } \\
\text { p/ bimestre }\end{array}$ & \multicolumn{2}{c}{ Nunca } \\
\hline a. & Observar & 48 & 87,3 & 7 & 12,7 & 0 & 0,0 & 0 & 0,0 \\
b. & Descrever objetos e fenômenos & 42 & 76,4 & 11 & 20,0 & 1 & 1,8 & 1 & 1,8 \\
c. & Debater & 52 & 95,0 & 3 & 5,0 & 0 & 0,0 & 0 & 0,0 \\
d. & Usar instrumentos como lupas, réguas, etc & 9 & 16,0 & 9 & 16,4 & 2 & 3,6 & 35 & 64,0 \\
e. & Levantar hipóteses e fazer comparações & 12 & 21,8 & 8 & 14,5 & 18 & 32,7 & 17 & 31,0 \\
f. & Trabalhar em grupo & 24 & 43,6 & 16 & 29,0 & 9 & 16,3 & 6 & 11,0 \\
\hline & & & & & & & & \\
\hline
\end{tabular}

Fonte: Da pesquisa.

Em relação aos dados sobre habilidades e competências desenvolvidas nas aulas de Ciências verificamos que a maioria das professoras faz trabalhos de observações e descrições semanalmente com as crianças. Mas, como e quais são as observações e descrições realizadas? 
O debate é também apontado como uma atividade frequente nas aulas. A nosso ver, também seria importante averiguar o que as professoras chamam de debate e a natureza desse discurso em sala de aula. Por outro lado, outras habilidades relacionadas ao ensino de Ciências como o uso de instrumentos, o levantamento de hipóteses e o trabalho em grupo aparecem em declínio, como mostra a tabela acima. Tais habilidades são apontadas como aspectos que aparecem esporadicamente nas aulas.

\section{CONSIDERAÇões FinAIS}

Nossa intenção ao realizar esta pesquisa foi identificar o perfil e as práticas docentes das professoras que ensinam Ciências nos anos iniciais. Assim, nosso estudo mostra que a maioria das professoras possui curso superior e que todas ministram aulas de Ciências há muitos anos, nos anos iniciais, pelo menos uma vez por semana. No entanto, esses aspectos não garantem conhecimento pedagógico na área de ciências, visto que poucas realizaram cursos de atualização ou, ainda têm oportunidade de refletir sobre o ensino dessa disciplina no interior das escolas. Assim, é necessário que as universidades e centros de formação repensem as disciplinas metodológicas que têm como objetivo auxiliar as professoras a pensar o ensino de Ciências em sala de aula.

Em suma, o ensino de Ciências é baseado, fundamentalmente, em atividades que requerem o uso de lápis e papel, de textos para leitura e questionários. As atividades experimentais são realizadas esporadicamente e são pautadas por uma concepção empirista.

A análise dos questionários evidenciou que a oralidade, a leitura e a escrita são práticas destacadas pelas professoras nos questionários. Contudo, essas questões também precisam ser investigadas no contexto. Também o papel do livro didático de Ciências nas aulas, em nossa opinião, é outro aspecto importante para reflexão, uma vez que as professoras possuem liberdade de fazer uso dele e até de fazer oportunas adaptações, tendo em vista as inovações curriculares proporcionadas. Além dos mais, o livro didático parece ser um instrumento que serve apenas como material de leitura e escrita para as crianças.

Concluindo, os resultados desta investigação demonstraram a necessidade que o planejamento das aulas de Ciências, a elaboração curricular e a avaliação devem ser discutidas com as professoras, para que possam reconhecer outras formas de ensinar. O conhecimento prévio das crianças também deve ser alvo de estudo das professoras para que elas se sintam mais seguras para desenvolver o trabalho. 
Assim lembrando Barros e Losada (2001), um dos aspectos mais importantes no ensino é a falta do desenvolvimento de conteúdo procedimental nas aulas de Ciências. Os professores reconhecem a importância das atividades práticas para desenvolver a aprendizagem de procedimentos; entretanto, os objetivos traçados são bastante comuns, como a observação e a manipulação. Reconhecem, também, a ausência de procedimentos relacionados ao pensamento científico, como a formulação de hipóteses, uso de instrumentos, descrições e comparações. Dessa forma, os procedimentos não são percebidos como habilidades a serem desenvolvidas. Em última análise, planejar a formação de professores demanda a reflexão sobre conteúdos procedimentais e atitudinais, para que eles possam incorporá-los em seus planejamentos de ensino.

\section{REFERÊNCIAS}

ALBUQUeRQUE, H. M.. P. A escola como ambiente educativo. In: Jornal APASE, São Paulo: Sindicato de Supervisores do Magistério no Estado de São Paulo, v. 13, n. 104, p. 5-8, jul. 2002.

ALMEIDA, S.A. Ver o invisível: as metamorfoses do aprender e do ensinar ciências em uma experiência de professoras do primeiro ciclo. Dissertação, Universidade Federal de Minas Gerais (2005).

ALVES-MAZZOTTI, A. J. Relevância e aplicabilidade da pesquisa em educação. Cadernos de Pesquisa, São Paulo, jul. 2001.

AUGUSTO T. G. da S.; AMARAL. I. A. A formação de professoras para o ensino de Ciências nas séries iniciais: Análise dos efeitos de uma proposta inovadora. Ciência Educação, Bauru, v. 21, n. 2, p. 493509, fev. 2015.

BORGES, R.M.R.; MORAES, R. Educação em Ciências nas séries iniciais. Porto Alegre: Sagra-Luzzatto, 1998

BRASIL, LDB, Lei 9394/96. Lei de Diretrizes e Bases da Educação Nacional. Disponível em: $<$ http://portal.mec.gov.br> Acesso em: 01/10/2012.

BRASIL. Secretaria de Educação Fundamental. Parâmetros Curriculares Nacionais : Ciências Naturais / Secretaria de Educação Fundamental. . Brasília : MEC /SEF, 1998.

CARVALHO, M. P. de. Trabalho docente e relações de gênero. Revista Brasileira de Educação. São Paulo: ANPED, n. 2, mai./ago, 1996.

COQUIDÉ, M. Um olhar sobre a experimentação na escola primária francesa. Revista Ensaio Pesquisa em Educação em Ciências, vol.10, № 1, 2008.

DELIZOICOV, N. C; LOPES, A. R. L. V.; ALVES, B. D. Ciências Naturais nas Séries Iniciais: características e demandas no ensino de Ciências. In: Encontro Nacional de Pesquisa em Educação em Ciências. Bauru, SP, 2005. 
FERNANDES, R. C. A. Tendências da Pesquisa Acadêmica sobre o Ensino de Ciências nas Séries Iniciais da Escolarização (1972-2005). 2009. Dissertação - Faculdade de Educação, Universidade Estadual de Campinas, 2009.

FUMAGALLI, L. O ensino de Ciências naturais no nível fundamental de educação formal: argumentos a seu favor. In: WEISSMANN, Hilda (Org.). Didática das Ciências Naturais: contribuições e reflexões. Porto Alegre: ArtMed, 1998.

Grupo de Avaliação e Medidas Educacionais. GAME. Perfil das Professoras das séries iniciais do Ensino Fundamental das Escolas Estaduais de Minas Gerais. FAE-UFMG, 1998.

GARCÍA BARROS, S.; MARTÍNEZ-LOSADA, C. Qué actividades y qué procedimientos utiliza y valora el profesorado de educación primaria. Enseñanza de las Ciencias, Barcelona, v. 19, n. 3, p. 433-452, 2001.

GATTI, B. Estudos Quantitativos em educação. Educação e Pesquisa, São Paulo, 2004.

GATTI, B. Os professores e sua identidade: o desenvolvimento da heterogeneidade. Cadernos de Pesquisa, São Paulo, n. 98, p. 85-90, ago.1994.

LIMA, M.E.C.C.; MAUÉS, E; Uma releitura do papel da professora das séries iniciais no desenvolvimento e aprendizagem de ciências das crianças. Revista Ensaio. Vol. 8. n.2. 2006.

MACEDO, M.S.A.N. (2004). Interações e práticas de letramento em sala de aula: o uso do livro didático e da metodologia de projetos. Tese de doutorado. Faculdade de Educação, UFMG.

NIGRO, R. G. AZEVEDO, M. N.. Ciência \& Educação, v. 17, n. 3, p. 705-720, 2011

SATHRES, S. M. et al. O ensino de Ciências nos anos iniciais do Ensino Fundamental: um viés para o exercício da interdisciplinaridade. In: Jornada Nacional da Educação, 12, 2006, Santa Maria.

UNESCO. Perfil dos Professores Brasileiros: o que fazem, o que pensam, o que almejam.../Pesquisa Nacional UNESCO. São Paulo: Moderna, 2004.

WEISSMANN, H. (org.). Didática das Ciências Naturais - Contribuições e Reflexões. Porto Alegre: Artmed, 1998.

Recebido em: 16 de abril de 2019.

Aprovado em: 09 de dezembro de 2019. 